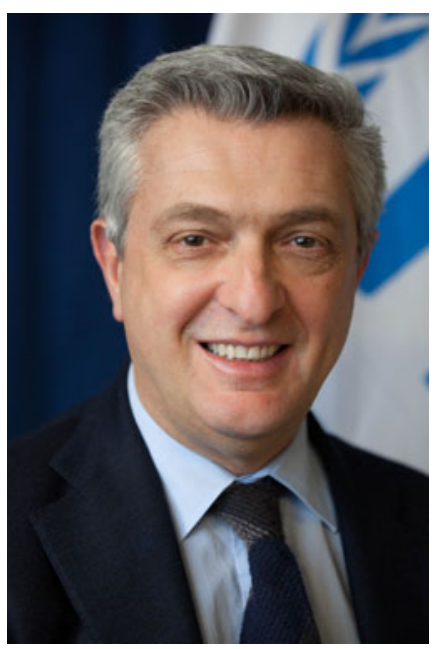

\title{
Interview with Filippo Grandi
}

\section{United Nations High Commissioner for Refugees*}

Filippo Grandi became the eleventh United Nations (UN) High Commissioner for Refugees on 1 January 2016. He has been engaged in international cooperation for more than three decades, primarily with the UN, and served in field operations in many of the major refugee and humanitarian crises of those years, including in Southeast Asia, the Great Lakes and Afghanistan. His previous appointments include CommissionerGeneral of the UN Relief and Works Agency for Palestine Refugees in the Near East, and Deputy Special Representative of the Secretary-General for the UN Assistance Mission in Afghanistan. As High Commissioner he is head of the Office of the UN High Commissioner for Refugees (UNHCR), the UN Refugee Agency, which leads the international response to refugee crises around the world, working with governments to ensure that refugees have access to protection and support, and helping find solutions to displacement and statelessness.

The tradition of providing refuge to people who are fleeing and in need of protection is a long-standing one, present throughout history and in various contexts, and now embedded in international law. The New York Declaration for Refugees and Migrants, adopted by the UN General Assembly in 2016, reaffirmed international refugee protection standards and provided a model for a more comprehensive response to large-scale refugee movements, based on shared global responsibility for refugees. It represented a critical development at a time when international cooperation aimed at preventing, responding to and resolving conflicts is proving inadequate, and an increasing number of people are being internally displaced,

* This interview was conducted in Geneva on 5 January 2018 by Vincent Bernard, Editor-in-Chief, and Ellen Policinski, Managing Editor of the Review. Special thanks to Jovana Kuzmanovic, Thematic Editor at the Review, for her work in preparing and editing this interview. 
forced across borders or left in protracted exile as a result of conflict, violence and persecution. In this interview, the UN High Commissioner for Refugees shares his thoughts on some of today's most significant forced displacement challenges, and the prospects presented by the New York Declaration.

Keywords: refugees, internal displacement, migrants, protection, UNHCR, Global Compact, international refugee law.

\section{You have had a great deal of experience in refugees and humanitarian work. Have you observed that the humanitarian needs of the displaced have changed during the course of your career? How has the response to those needs changed?}

The most fundamental change is in the global context in which humanitarian needs are generated, especially since the end of the Cold War. I first started working with refugees in 1984, with Cambodians in Thailand. This was a case involving a major conflict, and Cold War refugees. I worked for a non-governmental organization, and the people we found ourselves assisting included not only refugees but also some remnants of the genocidal Khmer Rouge, who, because of the Cold War context - they were escaping the current Vietnamese government, which was supported by the Russians - were given refuge in the West. There was support for this population by, among others, the United States, Thailand and China. The needs of refugees per se are not that different today from what they were then, as people need food, medicines and protection, but the global political context has profoundly changed.

Another change has been the magnitude of the populations affected. In twenty years, from 1997 to 2017, the number of people forcibly displaced around the world by conflict, violence and persecution has doubled - from almost exactly 33 to 66 million. Prior to the nineties, we did not really know how many internally displaced persons there were; this is also a matter of communication, better information and more access. The space for neutral, impartial humanitarian action was very limited, and the Cold War context precluded many organizations from accessing many of the people affected, especially in locations like Africa or Southeast Asia where major proxy conflicts were carried out.

Finally, it is interesting to see a different attitude to protracted refugee situations. Contrary to what is often said, these are not something new. A case in point is the Palestinians. Their displacement has lasted longer than any other group, and had already lasted for decades even when I started refugee work in the late eighties. However, there were many others as well. For instance, my first job with UNHCR at that time was in Sudan, where we dealt with Eritreans and Ethiopians who had already been refugees for more than twenty years. Protracted 
refugee situations clearly existed then, especially in Africa. The difference is in the way that they are dealt with. There were many more possibilities for integration of long-term refugees back then, and many examples of populations that were integrated in their host countries. The issue was less politicized, and States could absorb refugees who stayed for a long period of time more easily than is the case now. Talking about integration today is difficult, as many States are uncomfortable with that word for a variety of reasons that are often understandable.

\section{You mentioned that the refugee issue has had an underlying political dimension to it. Is the context different now? Is there less solidarity than in the past?}

I would not say that there is less solidarity now than in the past. It might be that solidarity has taken on different dimensions. In the past, the refugee issue was a humanitarian one, with its own legal aspects and specificities. The context itself was political, but the responses were seen as essentially humanitarian in nature. Today, the context is still a political one - people flee because of conflicts, which are political crises. However, the difference is in the responses, which were less controversial in those days.

The example of resettlement - which in the UNHCR language refers to bringing refugees from one country of refuge to another - is a good measurement of global solidarity. Traditionally, resettlement was mostly done from countries in Asia or Africa to the US, Canada, Europe or Australia. It is not required by any international treaty, but is a voluntary programme that governments offer with the aim of sharing, to an extent, the burden of countries hosting large numbers of refugees. Usually, it is aimed at giving opportunities to the most vulnerable refugees, such as women at risk, people exposed to particular protection risks, and so forth. Historically, resettlement played a fundamental role in crises such as the one in Indochina in the eighties. Integration was always a difficult issue in Asia. At the time, countries like the US, Canada, France and Switzerland agreed to take a large number of refugees from Vietnam and Laos. These humanitarian resettlements, which were also well resourced, could be thought of as models of humanitarian response.

Another similarly good example would be the concept of temporary protection. When the Bosnians fled, UNHCR crafted the concept of temporary protection - an exceptional measure to provide people unable to return to their country of origin with immediate protection in the context of mass influxes. Germany and other countries responded rather quickly.

Additionally, there is the example of emergency evacuation. In 1999, UNHCR had to negotiate the emergency evacuation of Kosovo refugees. The Former Yugoslav Republic of Macedonia did not want to let anyone in, which caused a blockage of 100,000 people at the border. UNHCR worked with States and evacuated them in a matter of days. Hence, one can say that this was 
political but not politicized. There was a sense of urgency to find solutions and certain States came readily to help. I think in that sense solidarity has changed.

Conversely, if one looks at Europe in 2015-16, there is a lot of solidarity among ordinary people. I think that that has not gone away. The "Western" governments have become timid in proposing solutions for refugees, especially if that means taking them in their respective countries. The usual response to this concern is the risk of losing political capital. Undoubtedly, a part of public opinion is against these solutions for refugees. However, rather than avoiding action, political leaders and governments should perhaps invest in that part of public opinion that is very open to solidarity.

The question remains as to why governments do not listen more. The challenge is for all of us to prop up this public opinion, interact with the public and help them become actors of solidarity in a way that influences governments in the right direction.

\section{Some in the academic and humanitarian community would argue that the term "refugee", as it is understood in the 1951 Refugee Convention, ${ }^{1}$ is too narrow given the varied drivers of displacement. How does UNHCR address these concerns? How would you address the calls to renegotiate or expand the definition found in the 1951 Refugee Convention?}

The fundamental point is that any renegotiation of terms in the current international context is quite dangerous. The definition is very clear when it comes to refugees fleeing persecution. One should note that it has proven to be adaptable to different situations forcing people to flee against their will, and especially to flight related to different forms of conflict and violence. Man-made circumstances, in particular, evolve with the passage of time. For example, many of the people fleeing from violence perpetrated by gangs in Central America are considered to be refugees as they have lost the protection of their State. This capacity for adaptation to contemporary forms of persecution and violence stays very clearly within the spirit of the 1951 Refugee Convention.

As well as the 1951 Refugee Convention and its 1967 Protocol, there are now also regional instruments: the Convention adopted by the Organisation of African Unity in 1969, the 1984 Cartagena Declaration and the European Union asylum framework. These instruments are very valid, usable and used, and they complement the big vision of the 1951 Refugee Convention. Over the decades, they have also helped UNHCR adapt its responses.

1 Editor's note: Under Article 1(A) of the 1951 Refugee Convention as amended by its 1967 Protocol, a refugee is someone outside his or her country of nationality or habitual residence owing to a wellfounded fear of persecution for reasons of race, religion, nationality, political opinion or membership in a particular social group, and who is unable to enjoy protection from his or her own State. 
I would agree that today the situation is more complex than in the past. However, I do not think that the definition of "refugee" is weakened and that unless it is reviewed or broadened it loses its effectiveness. The 1951 Refugee Convention is actually a very versatile document. There might be some parts of it that are less relevant today, such as the ones that dealt with transitional arrangements and so forth, but by and large, the Convention is a very current document that can be very actively utilized and which can - and does - save lives.

Further, the issue of climate change and so-called climate-related refugees or forcibly displaced persons is a very complex one. We have been asked to be part of the debate on people moving for climate-related reasons, and we have also participated in responses to natural disasters - for example, in the Philippines and in Pakistan during the floods. Our role there has been to move into responses that are not those related to traditional refugee movements, meaning conflict- or persecution-related. We have transferred our expertise in dealing with the consequences of those movements to circumstances which were similar, in particular as regards protection risks.

Admittedly, one of the biggest challenges today is that of mixed flows. In Libya or, to an extent, Central America, some people are clearly identifiable either as refugees or non-refugees, but then there are many others whose situations require a more complex analysis which demands a lot of time. This is quite a challenge.

It is important to maintain the distinction between refugees and migrants. We do not say that all those on the move are migrants and some of them are refugees, but rather that some are refugees and some are migrants. It is important to be clear that refugees are outside their countries and are unable to return for very specific reasons related to conflict and persecution. Migrants may also have problems, but they are different in nature. It is important to maintain this distinction while recognizing that movements, especially if they happen in parallel, have many common features which need to be addressed comprehensively, and not just by category. The most obvious examples are trafficking and slavery.

\section{Most recently, a lot of media attention has been dedicated to the so-called "refugee crisis", much of it focused on refugees crossing the Mediterranean to reach Europe. What challenges and opportunities does this type of media attention bring for UNHCR?}

This is a crucial question, and the reply has several aspects. We have always thought that attention is good because it brings resources and in some cases energizes the search for solutions. To an extent, this is also true for the Western and Central Mediterranean crises that have affected Europe in the past three years.

However, there are downsides. One is the nature of this type of media communication. The global refugee crisis is almost entirely a crisis affecting the countries in the global South. Around $84 \%$ of refugees are hosted in developing 
countries, not in the global North. Yet, because of the people arriving to Europe, in particular in 2015 and 2016, this is often portrayed as a European crisis or a crisis of the "rich world". Unfortunately, there is also political manipulation around it, portraying it as an "invasion" or merely an attempt by people to get better opportunities. On the contrary, however, the global refugee crisis is essentially one of people seeking protection and safety, and fleeing conflict. This is a fundamental issue that gets lost in this perspective. Such is the downside of a continent which is at the heart of global communications being affected in this manner, and for the first time. The only other equivalent that I can think of is the Balkans in the nineties, but that example was different in nature as it was a "Europe to Europe" crisis. In comparison, the current perception emerged when African and Middle Eastern citizens started coming in large numbers to Europe. Even though this was maybe not so dramatic, the political manipulation coupled with the media visibility caused a lot of damage.

As a consequence, the effects in Europe today entail restrictive legislation, inability to craft a common European approach to handle the crisis - as seen in the very limited success of the relocation scheme - and no progress in the current discussion on a Common European Asylum System. Some countries, influenced by all that has happened, do not want to agree on shared solidarity measures.

Apart from the negative effects of this visibility in Europe, there is also a global effect. Some countries of the global South are being asked to keep borders open, or to continue to host refugees that have been there for several generations. Every time I visit them, I get asked many questions in reference to the demands put on them by "rich countries" as well as their responses. The reality is that the negative visibility given to the crises by unscrupulous politicians is affecting UNHCR's ability to work with States that host the bulk of the refugees. One illustrative example is Kenya. This was one of my first crises as High Commissioner. I went there three or four times last year to try and address the pressure to close the Dadaab refugee camp. The Kenyan government referred to the fact that these refugees, perceived as a security threat, have been there for twenty-five years. There were demands to find a solution, either to work towards peace or in any case for Somalia to receive the refugees back. Interestingly, it was emphasized that "rich countries" also voice the same concerns, but still push people back or do not take them in. Therefore, the question arose as to why Kenya, with much fewer resources, should respond differently. It is important to note that in these situations, especially the protracted ones, resources have dwindled. Unfortunately, after the first few years it is very difficult to continue to resource a response in the traditional manner.

Consequently, the negative role of the media visibility is very difficult to handle. What does not always come to mind, but is very damaging, is the problem of setting a negative example. People sometimes realize this when I say it in a public speech. Europeans usually do not have a problem in saying that Kenya or Pakistan should take refugees, but reactions change when it is about them. Challenging this attitude usually results in the answer that this problem is a political one in Europe. However, this is a political problem in places like 
Lebanon, Kenya and Pakistan as well. The failure to recognize this is almost "colonial" in nature.

My final point is more on the positive side. As it was Europe that was hit so visibly and dramatically, this generated important debates in the last part of 2015 and 2016. The debates ranged from the topic of the humanitarian-development nexus and how to become concrete in addressing long-term crises, to working on more predictable and better resourced responses to refugee emergencies. The discussion at some point moved into the UN General Assembly and generated the New York Declaration and the process that will hopefully lead to the adoption of the two Global Compacts. This would not have happened, in my opinion, if the visibility of that crisis had not prompted lots of countries to say that something needed to be done. We need to try and find a response that is better than we have managed so far.

\section{Turning to the two ongoing Global Compact processes, on refugees and migration respectively, could you tell us more about their significance and what is expected from them?}

When it comes to the Global Compact on Refugees, UNHCR has been tasked by the General Assembly with facilitating the process. We have concluded a first year of informal consultations with States, civil society and other organizations and have entered into the second year of formal consultations on a draft text.

The idea is to obtain a document or a tool which does not put into question the fundamental principles and standards. It will be based on the existing doctrine, with the aim of reinforcing it and finding a better way to respond to crises. The Compact on Refugees is an agreement between all States that there is a problem and that there are certain rights enshrined in international law, and refugee law more specifically, that the people in question enjoy. However, the responses have been very inadequate. This is especially true for big crises in terms of resources and sharing responsibility.

When it comes to expectations, the Compact on Refugees started on a good footing, as the New York Declaration already spoke about this in Annex I, which has become known as the Comprehensive Refugee Response Framework. We want that framework - which has already been agreed to by 193 States - to become the basis of the Compact, together with a programme of action, which will make certain commitments and engagements by States more concrete.

Many questions were put forward in the first informal phase of the process. How to become more effective in raising resources? How to become more predictable in mobilizing the logistical capacity to respond to big crises? How can development actors intervene at an early stage so that we can invest in areas that have been traditionally underfunded, like education and employment? How can the international community better support host communities, especially in largescale situations? These, and others, are all lingering issues that have always existed, but we have never been able to make responses very predictable because 
there was never a drive to agree to a plan of action. Whether this will be translated into better responses will depend on States, but we will have a framework of reference that will be very important.

It is also very important that the framework is applied on the ground, and this started immediately after the adoption of the New York Declaration. Uganda was the first country where it was applied, and now thirteen countries are already rolling out the comprehensive model. This has four key components: easing pressure on host countries and communities; building the self-reliance and resilience of refugees and hosting communities, as opposed to responding purely to humanitarian needs, which remain important; developing more resettlement opportunities and legal pathways to other countries; and building conditions for voluntary return.

Many lessons are already emerging from this experience, both positive and negative. Regional approaches have been put in place in Central America, for instance, and for Somali refugees in the East and Horn of Africa - an approach that was endorsed at heads-of-State level in Nairobi in March 2017. In several countries in Africa there is also a country-by-country approach, and some countries in Asia are also considering joining. The key takeaway is that even though this is not a new Convention in the making, States are asked to make certain commitments. In particular, one should emphasize the call for mobilizing financial resources as well as more resettlement, and on the part of the host countries, the call to give refugees more access to public services and the labour market. This is a more inclusive approach than putting refugees in camps and keeping them there for twenty years. The idea is not to open more refugee camps, but rather to allow refugees to be included in the local economy and public services for as long as they need to be in that country.

Clearly, there are numerous ideas but many are not really new. The achievement is that they are now all presented together in one document - which, once approved, will enjoy the endorsement of all States, giving it particular strength at an international level.

The development of the Global Compact for Safe, Orderly and Regular Migration (Migration Compact) is in certain respects more complex, as it starts from a much more limited doctrinal basis. Clearly, migrants have human rights, but there is no equivalent instrument to the 1951 Refugee Convention or the regional refugee frameworks. This makes it a more challenging process. As UNHCR is a contributor to that debate, the main interest is to make sure that the common issues are addressed in a manner which is harmonious between the two Compacts, while at the same time making sure that the particular status and rights of refugees are upheld.

It should be noted that a strong and solid Migration Compact is important for refugees as well. If migration is managed better than is currently the case, this will have a positive impact on the way in which refugee flows are addressed. For one, a lot of people that currently move, not for reasons of persecution or violence but to look for economic opportunities, would be less inclined to resort to asylum claims as their only channel to get into countries. Providing safe, regular migration 
opportunities would help alleviate undue pressure on the institution of asylum, which is already challenged, and often fragile. The Migration Compact is very important and is, at least, the starting point of a better way to manage migration - more effective, more respectful of people's rights but also more useful to States. In a way, the two Global Compacts are very complementary and it is important that they move together in parallel. It would be unfortunate not to have consensual compacts, because in the end, the fundamental issue is that people on the move, be they refugees or migrants, are not an isolated phenomenon any more. These are issues of global interest which need global responses.

\section{There is a lot of talk around the topic of "burden-sharing" or "responsibility-sharing". What, concretely, will the Global Compact on Refugees do to facilitate responsibility-sharing between States?}

There are three key things. The first one is more resources, but resources of a different nature. For years now we have been battling to mobilize more humanitarian resources through the traditional means, but these efforts have been outpaced by growing needs, and we are now pretty close to hitting the outer limits. In particular, protracted displacement situations that do not offer much chance for local integration generate needs that humanitarian resources cannot fully respond to, like education, livelihoods, employment benefits and the whole array of needs that pertain to the local communities that host refugees. We hope the Global Compact on Refugees, underpinned by much stronger, earlier development action including new financing instruments, will address this. If done on a broad scale, this can represent much more substantial burden-sharing.

The second key aspect is resettlement. Resettlement is not and will never be the solution for a large number of people. Last year we were able to find places for around 75,000 refugees, representing a very small proportion of the refugees that fall under UNHCR's responsibility, who are now approaching 19 million. This is much less than $1 \%$ of the total number - and also represents a fall of around $50 \%$ from 2016. We believe the number of resettlements can and should be much bigger. This is a very powerful aspect of burden-sharing.

An illustrative example would be the Dadaab camp. Indeed, a third generation of refugees is now growing up there, in an isolated area of Kenya. This is not a good solution for anyone. We did not want them to be pushed back to Somalia, but we agreed with the government that we needed to "unpack" Dadaab and look at different solutions: resettlement, local integration for people that were of mixed Somali and Kenyan heritage, transfers to other parts of Kenya, voluntary repatriation to Somalia for those that wanted to go back. However, this could be done only by Kenya, UNHCR and Somalia together; we needed a joint effort, and help from other governments. This is an 
embryonic example of broader solutions. The reduction in resettlement to the US has come at an unfortunate time, in the middle of this situation. The US went from officially accepting 110,000 refugees a year - although this ceiling was not in the end reached in practice - to fewer than half that number last year. This, of course, goes against the notion of shared responsibility. We would actually like countries to increase their quotas, as many countries in Europe are now planning to do.

The last key point is more awareness on the part of public opinion and civil society. We are trying to find ways through which the business community, both international and local, can become involved in responses.

\section{In the humanitarian sector today, which is increasingly expanding in terms of local, regional and international actors, how is UNHCR's experience in partnering with other organizations? What new opportunities do you see?}

From its very beginnings, UNHCR worked through or with partners. These were mostly local and international NGOs and sometimes National Red Cross and Red Crescent Societies.

In the past twenty years UNHCR has gone through a complex exercise in moving from partners that are essentially recipients of our funds to more strategic partnerships based on collaboration and complementary expertise. For instance, we partner with many NGOs that have developed very good protection skills, which years ago was an area in which we were essentially working by ourselves. Overall, on the NGO front, although it is always quite dynamic and there is a lively debate, I think we work well together. However, the areas where we need to learn a lot more - and I see the Compact on Refugees as an opportunity for this - are the development partners and the private sector.

When it comes to development partners, we are fortunate to have very visionary leadership at the World Bank. On the UN side, we have invested a lot in this relationship and have made huge strides. The World Bank has created a fund, under its International Development Association IDA18 replenishment process, to provide targeted development support to countries and communities hosting large numbers of refugees, and together with other stakeholders has also developed financial instruments for middle-income countries affected by large refugee flows, such as Lebanon and Jordan. Yet, we still need to advance and learn more, in terms of language, tools and analysis, in our interaction with the development partners. This is true for the World Bank, and also other financial institutions and major bilateral entities like the European Union. At the same time, these prospective partners also need to learn our way of reasoning, operating and analyzing. The cooperation with the World Bank has been very successful - it now uses us as a sounding board with regard to its allocation of refugee-related funds through grants, loans, soft loans and other instruments. We help analyze the relevant data, learning a lot in the process. This opens up 
enormous possibilities - in particular, the resources in question are considerably bigger than those we can ever mobilize in the humanitarian world, and the World Bank also brings into the equation its capacity to analyze data, especially economic data. These are capacities that we never had before, as this is not our area of expertise.

The other area is the private sector. For a long time the private sector was considered essentially a donor or a giver of charity. This remains to some extent true today, but many private donors are also expressing their willingness to partner with us and be a part of how we programme. This has many benefits, as they have significant expertise in areas of technology, business models, employment schemes and training, especially skills training. They bring in additional resources, new approaches and new expertise, and can create a lot of awareness. Often, they are large companies that have a lot of employees and big markets, which means they give publicity to what they do and create awareness about positive approaches to refugees. I am a big believer in this. At the same time, it is also very challenging because of the gap in conceptual approaches, which is even bigger than with development organizations.

The interest in preventing atrocities seems to be gaining pace already twenty years ago, UNHCR had spoken about early warning. The link between respect for international humanitarian law (IHL) within the frame of conflicts to prevent forced movement of populations has been very present in the international discourse. How do you see this interest in prevention? What is your contribution to it as the head of UNHCR?

It is true that conflicts have become very harsh on civilians, maybe harsher than they used to be. Civilians have always been targeted in all wars, but after the Cold War ended, starting from the Balkans, the Great Lakes and so on, there seems to be more license to target civilians than was the case before. This is a major cause of flight, and IHL violations are a fundamental element in the decisions of people to flee. The risk of their houses being destroyed, their life or freedom being threatened, or forcible recruitment, for example, are important factors in driving displacement. I think that respect for civilians in conflict would be a formidable measure for preventing forced displacement. We know how difficult that is, but the discussion on prevention is very important, and for it to be effective there needs to be a minimum of political will. From the UNHCR side, we offer information coming from our observations of population movements and conversations with refugees as systematically as possible. We also share this information with our political colleagues in order for them to have a better analysis of looming conflicts. This is more early warning than prevention. Importantly, the current Secretary-General, who was my predecessor as High Commissioner, has a very clear sense of the importance of 
early warning and prevention. There is now more awareness in New York that a "humanitarian" read-out of these situations - for example, in relation to the Congolese refugees leaving the Democratic Republic of the Congo for Angola last year - is important to help address conflict at a very early stage. Other than that, it is really a political matter.

\section{With all the ongoing international processes you mentioned, the challenges and the need to work together to find solutions, what do you see in the future for UNHCR?}

My mandate as High Commissioner for Refugees has two aspects: protection of refugees and other people of concern to UNHCR, and working with States to find solutions.

The narrative on the crisis of protection is unfortunately very true, but so is its twin evil - the crisis of solutions.

The end of the Cold War raised expectations that we would be able to solve conflicts, but these have been met with a lot of disappointment for a variety of reasons. The only conflict that was solved in 2017 was Gambia. António Guterres, assuming office as UN Secretary-General at that time, saw Gambia as a very good model. ECOWAS [the Economic Community of West African States] successfully worked on prevention, so that the conflict would not erupt and become worse. Unfortunately, it stopped there, and no other conflict was resolved last year. Clearly, this is a big obstacle in carrying out our mandate. One has to navigate extremely complex situations in which solutions are not clear and, for the majority of people, are simply not there.

Considering this pressing and ongoing need for solutions, at UNHCR we are establishing a new division - the Division of Resilience and Solutions - that will be overseen by Volker Türk, our Assistant High Commissioner for Protection. By focusing on resilience, we can concentrate our efforts on transforming the circumstances of refugees that are stuck in long-term situations and on keeping them, and the communities hosting them, strong until a solution happens.

The crisis of solutions obliges us to look at intermediate issues, but in a different manner. I think this crisis of solutions is linked very much to the prevention discussion. It is a fundamental challenge. In the nineties we had a lot of hope, but unfortunately many of those hopes have not been met.

Moving forward, we must be both ambitious and realistic. The New York Declaration was, I believe, an important reaffirmation at the highest level of the values and standards of international refugee protection, at a time when these were being called into question by many. It has provided us with an important platform for engineering real changes to the response system and making it much more robust, comprehensive and sustainable. Political attention is constantly shifting, especially around a charged issue such as refugees and migrants, and we can certainly anticipate challenges and setbacks ahead. It can be very tempting, in 
circumstances like these, to say "it's impossible" - but we absolutely cannot. We have to confront the challenges, and to take up the important responsibility of turning the political commitments of the New York Declaration into something very concrete, with a real impact on people's lives, and to avoid making them hostage to volatile politics. This is essentially what the Global Compact on Refugees hopes to achieve. 